\title{
QUE FAREI(S) COM ESTE LIVRO? : UM EXERCÍCIO DA MEMÓRIA CULTURAL PORTUGUESA
}

\section{Teresa Cristina Cerdeira da Silva*}

... todos os cami nhos portugueses väo dar a Camōes, de cada vez mudado consaame as olhos que o veem, em vida sua braço is armas feito e menie is musas dada, agora de espada na bainha, cerrado olivro, os ol hos cegas, a mbos, tanto lhas picam as pombos como as olhares indiferentes de quem passa.'

JOSÉ SARAMAGO

o escolher, entre os livros de José Saramago, a peça de teatro -
Que farei com este livro? - como ponto de partida para estas
reflexões sobre a questão da memória e, mais especificamente, do resgate da memória cultural portuguesa, levanto mais que um exemplo de texto que relê Camões de forma quase emblemática e Os Lusíadas como livro fundador de uma cultura. Porque, mais do que a questão aparentemente fundamental que dá título à obra - Que farei com este livro? - questão que se centra na angústia individual de um poeta em crise para a divulgação do seu texto, subjaz uma outra, esta sim, verdadeiramente sedutora, que se insinua ao longo de todo o segundo ato da peça e é enfím pronunciada pelo épico quase ao desfecho da última cena: "Que fareis com este livro?". Esta é a questão que atrai verdadeiramente e que norteará minhas reflexões, porque é já do destino de um livro que se trata, da memória que dele construirão que pretendo falar, a sua recepção e a apropriação da sua voz

'Universidade Federal do Rio de Janeiro

1 SARAMAGO, J. (1984), p. 181 
pela voz do outro que me interessa. E com isto estarei a falar de um diálogo de textos, de uma conversa que os séculos não anulam, ao contrário, que o tempo parece sempre enriquecer em sua diversidade. No caso presente trata-se da voz de Camões em sintonia com a de José Saramago, numa primeira instância, e com toda a cultura contemporanea portuguesa, de maneira mais geral.

Esta sintonia interessa, inicialmente, como postura teórica: a obsessão da contemporaneidade pela releitura de outros textos, a proposta de revista a tradição para traduzi-la como criação, o fascínio da memória cultural que, longe de surgir, necessariamente, como modelo edificante e intocável, vê-se apreendida, incorporada e, por vezes inverida. O objeto estético assim violado em sua inteireza - ao se fazer corpo revisitado - perde a aura que lhe conferia o selo único do autor, mergulha na incerteza produtiva porque geradora do novo. Se a intertextualidade não é apanágio da pósmodernidade, é, entretanto, aí que a ousadia da apropriação parece ganhar corpo e o diálogo intertextual ultrapassar o eco das referências intelectuais, que justificam o reconhecimento de uma cultura humanística, para se transformar no centro de interesse da ficção, roubo salutar de uma liberdade que ousa deslocar os mitos perturbadores - como ousar escrever depois de Os Lusíadas, como ousar compor depois do Quixote? - para devorá-los e devolvê-los em outra produção. Viver a contemporaneidade é também perceber que o tempo de fascinio de absoluto foi ultrapassado por um diálogo mais democrático com a tradição. E, ao revisitar, de igual para igual, os mitos do passado, escapa-se, não só ao silêncio da criação sufocada pelo modelo incorruptível e tutelar, como, sobretudo, acorda-se, com o gosto novo, a possibilidade de vida que a tradição pode conter quando ultrapassada a relação imitação/modelo.

Podemos parecer estar longe da proposta inicial e, no entanto, talvez não. Voltemos ao mote: "Que fareis com este livro?, frase, como já sabemos, pronunciada por Luís de Camões enquanto personagem da peça de José Saramago. Claro que nós poderíamos deixar seduzir por um viés da questão: o da apropriação redutora e injusta que os discursos totalitários fizeram, ao longo dos séculos, dos versos d'Os Lusíadas, transformados em propaganda fascista e desolador discurso patriótico. Tal angústia do poeta ecoa na fala do narrador de $O$ ano da morte de Ricardo Reis citada na epígrafe, angústia de um poeta que se saberá "mudado consoante os olhos que o vêem", num processo de constante degradação: da conhecida semicegueira aos "olhos cegos, ambos", do "braço às armas feito" à "espada na bainha", da "mente às musas dada" ao livro "cerrado" como o traduziu, em pedra, a posteridade. 
Mas a mesma questão, pronunciada ao encerrar-se a peça, bem poderia ser lida como o dom de texto que haveria de correr os séculos, incessantemente relido. A obra de José Saramago, como outras tantas da literatura contemporânea portuguesa, passando pelAs Naus do Lobo Antunes, pela Lusitânia de Almeida Faria, para só citar dois romancistas, é um exemplo, entre outros, dessa sedução, dessa ousadia com o passado, que opta pela intervenção, e não pelo silêncio, para evitar a catástrofe da castração do gozo da escrita diante da presença obsidiante do texto magistral de Camões. A interlocução é a opção consciente pelo resgate da memória que se lança, como construção, em direção ao futuro. Fazer Camões presente na leitura que dele se faz, representá-lo em outros textos, é, de certa forma, dar uma resposta possivel à questão: "Que fareis com este livro?". Saramago respondeu, a seu modo, ao traçar o caminho da épica alentejana em Levantado do chão, onde certamente se pode afirmar que um outro valor da terra se alevanta; mas o fez também na imaginação de uma épica do ar que a passarola do Memorial do Convento, fruto da contribuição harmônica da ciência e da arte, do artesanato e da magia, ousou empreender num tempo remoto em que só à ficção era possivel voar; c na anti-épica viagem de retorno de Ricardo Reis a Lisboa, num vapor inglês da Mala Real Britânica, que ocupava o Tejo das naus portuguesas de outrora, tudo parecia indicar que, num tempo de mares longamente navegados, o momento era o do desembarque para a vigilia na terra, num ano de 1936 que se anunciava desesperadamente dificil para quem acreditara que "sábio é o que se contenta com o espetáculo do mundo"; há ainda um certo Camões na navegação, enfim venturosa, que já não deixa a lira destemperada ou a voz enrouquecida, de uma Jangada de Pedra - península que se desloca voluntariamente do envelhecido continente para ocupar seu lugar cultural na bacia atlântica que agora revisita para reencontrar-se como irmã. Em cada um destes textos ecoa, de uma forma ou de outra, a memória de Os Lusíadas. E, podemos dizer, que a exemplo de Pirre Ménard, José Saramago se fez seu ator. Borges ousara com o Quixote, em Portugal o mito é evidentemente outro. Como no modelo borgiano, ao dizê-lo outro ele o refaz, e até ao dizer o mesmo, a invenção é cvidente. Quando descreve a despedida dos trabalhadores que partem obrigados para o trabalho em Mafra (Memorial do Convento), o romance revisita o Velho do Restelo: no grito das mulheres violadas: "Maldito sejas até a quinta geraçāo, de lepra se cubra o corpo todo, puta vezas a tua mãe, puta a tua mulher, puta a tua filha, empalado sejas do 
cu atc a boca, maldito, maldito, maldito" ${ }^{2}$ ressoa a memória literária que recupera a maldição de outrora - "Maldito o primeiro que, no mundo, / Nas ondas vela pôs em seco lenho" (IV, 102), acentuando o tônus dramático com a linguagem chula; revisita-o, ainda, na repetição literal do pranto das mães c esposas: "acompanham-nos até fora da vila as infelizes, que vão clamando, qual em cabelo, Ó doce e amado esposo, e outra protestando, Ó filho, a quem eu tinha só para refrigério e doce amparo desta cansada já velhice minha" ${ }^{3}$; ou ousa acrescentar, ao decassílabo mais-que-ilustre "Ó glória de mandar, ó vā cobiça", outro que a ele se une em ritmo e rima ordenado, para insinuar que o tempo é outro e o texto tem novas exigências: "Ó glória de mandar, ó vã cobiça, ó rei infame, ó pátria sem justiça." ${ }^{4}$

$O$ que a releitura dos textos faz com o original abala-o, certamente, enquanto versāo única e insuperável de uma magistral criação mas the devolve uma outra permanência, feita da possibilidade de se ver multiplicado e acordado em outras vozes que foi capaz de originar, evitando assim o destino precário que o narrador "Pierre Ménard, autor do Quixote" ousara prever para as obras-primas:

\footnotetext{
Não hả exercicio intelectual que não resulte ao fim inútil. Uma doutrina filosófica é no principio uma descrição verossimil do universo; os anos giram e é um simples capitulo - quando não um parágrafo ou um nome - da história da Filosofia. Na literatura, essa caducidade final è ainda mais notónia. O Quixote - disse-me Ménard - foi antes de tudo um livro agradável; agora é uma ocasiāo de brindes patriótioos, de soberba gramatical, de obscenas ediçōes de luxo. A glória é uma incompreensảo e talvez a pior. ${ }^{5}$
}

Os "brindes patrióticos", a "soberba gramatical" e as "edições de luxo" estão para o Quixote, como os "olhos cegos", "o livro fechado" e a "espada na bainha" estão para Camões e os Os Lusiadas. E não é este, certamente, o destino que o épico imagina para o seu texto ao perguntar: "Que fareis com este livro?" De certa maneira, a contemporaneidade aposta no palimpsesto, nesse tex to final e outro que, guardando os rastos tênues de um texto primeiro, se permite viver, não como rapina, que o devora e anula,

2 SARAMAGO, J. (1983), P. 293

$3 \quad$ ibid, p. 293

$4 \quad$ ibid, p. 293

S BORGFS. J.L. (1983). p. 50 
mas como possibilidade de perpetuá-lo na diferença e no convivio com a multiplicidade de textos que, dizendo com as mesmas sedutoras palavras, vão elaborando versões sempre novas da memória dos homens.

\section{RESUMO}

Intertextualidade e memória cultural. A sedução / obsessão de $O s$ Lusiudas na cultura portuguesa. Permanència na transformação: antropofagia salutar. O texto contemporáneo como palimpsesto.

\section{REFERÊNCIAS BIBLIOGRÁFICAS}

I. BORGES, Jorge Luis. Fictions. Paris: Gallimard, 1983.

2. SARAMAGO, José. Memorial do convento. São Paulo: Difel, 1983.

3. . O ano da morte de Ricardo Reis. Lisboa: Caminho, 1984.

4. . Que farei com este livro? Lisboa: Caminho, 1980. 